\title{
Open repair of chronic distal aortic dissection in the endovascular era: Implications for disease management
}

\author{
Akshat C. Pujara, MD, ${ }^{\text {a,b }}$ Eric E. Roselli, MD, ${ }^{\text {a,b }}$ Adrian V. Hernandez, MD, PhD, ${ }^{\text {bc }}$ Lina M. Vargas \\ Abello, MD, ${ }^{\mathrm{a}, \mathrm{d}}$ Jacob M. Burke, ${ }^{\mathrm{a}}$ Lars G. Svensson, MD, PhD, ${ }^{\mathrm{a}}$ and Roy K. Greenberg, MD ${ }^{\mathrm{a}, \mathrm{d}}$
}

\begin{abstract}
Objective: Controversy surrounds the treatment of chronic aortic dissection. Open surgical and endovascular experiences include mixed populations treated with evolving strategies and limited follow-up. We establish a standard against which endovascular repair can be compared by assessing outcomes after open repair of chronic distal aortic dissections anatomically suitable to stent-grafting.
\end{abstract}

\begin{abstract}
Methods: From 2000 to 2008, 169 patients underwent open repair of the descending thoracic artery only $(\mathrm{n}=88)$ or thoracoabdominal $(\mathrm{n}=81)$ chronic aortic dissection (elective in 98 , urgent/emergency in 71$)$. Chart review and 3-dimensional assessment of computed tomography were performed. Poor outcome included allcause mortality or vascular reintervention.
\end{abstract}

Results: Thirty-day mortality was $8 \%(n=14)$. Serious complications included neurologic $(n=12$ [spinal cord $\mathrm{n}=4,2.4 \%])$, respiratory $(\mathrm{n}=32)$, and renal failure $(\mathrm{n}=1$ descending thoracic artery only vs 17 thoracoabdominal, $P<.001$ ). Chronic obstructive pulmonary disease predicted early mortality (hazard ratio 8.0, $P=.005)$. Survival at 1,2 , and 5 years was $76 \%, 69 \%$, and $55 \%$, respectively; 23 patients $(14 \%)$ required reintervention. Event-free survival at 5 years was $51 \%$ and $47 \%$ after descending thoracic artery only or thoracoabdominal repair, respectively. Greater maximum aortic diameter (hazard ratio $1.9, P=.03$ ) and greater diameter at the diaphragm (hazard ratio 3.7, $P=.01$ ) or renal segment (hazard ratio 4.3, $P=.03$ ) predicted poor outcome.

Conclusions: Early outcomes are good and late outcomes are less than desirable after open repair of chronic distal aortic dissection, regardless of the extent of repair. High-risk and late-stage patients with larger and more extensive aneurysmal degeneration warrant further investigation, including the use of newer, lessinvasive techniques. Select patients at risk for aneurysmal degeneration should undergo a more aggressive initial approach with aortic dissection repair. (J Thorac Cardiovasc Surg 2012;144:866-73)

The number of patients with chronic aortic dissection is increasing as more patients are surviving the acute phase because of progress in open surgical, endovascular, and medical treatment paradigms. ${ }^{1}$ Although the number of endovascular procedures performed on the dissected distal aorta has increased over the last decade, controversy exists regarding the preferred approach in patients who require intervention, especially those with chronic disease. ${ }^{2-4}$ Much of the current literature pertaining to open repair of aortic dissection describes a heterogeneous population of mixed acuity and extent of disease, and does not include

From the Department of Thoracic and Cardiovascular Surgery, ${ }^{a}$ Cleveland Clinic Lerner College of Medicine of Case Western Reserve University, ${ }^{b}$ Department of Quantitative Health Sciences, ${ }^{\mathrm{c}}$ and Department of Vascular Surgery, ${ }^{\mathrm{d}}$ Cleveland Clinic, Cleveland, Ohio.

Funding: This work was supported by an award from the American Heart Association.

Disclosures: Authors have nothing to disclose with regard to commercial support. Received for publication Nov 24, 2010; revisions received Nov 26, 2011; accepted for publication Jan 4, 2012; available ahead of print Feb 20, 2012.

Address for reprints: Eric E. Roselli, MD, Department of Thoracic and Cardiovascular Surgery, Cleveland Clinic, 9500 Euclid Avenue, Desk J4-1, Cleveland, OH 44195 (E-mail: roselle@ccf.org).

$0022-5223 / \$ 36.00$

Copyright (c) 2012 by The American Association for Thoracic Surgery doi:10.1016/j.jtcvs.2012.01.021 follow-up imaging analysis. Furthermore, treatment periods span multiple decades. The objective of this study was to assess early and late outcomes after open repair of chronic distal aortic dissection. This experience with a comparable subset of contemporary patients may serve as the open standard against which endovascular interventions can be evaluated as they evolve.

\section{MATERIALS AND METHODS Patients}

From January 2000 to December 2007, 515 patients underwent open surgical repair involving the descending thoracic aorta (DA). Of these patients, 197 had chronic aortic dissection, defined as more than 14 days and after hospital discharge from the initial event. ${ }^{5}$ Twenty-eight of these 197 patients were excluded from the analysis because they were not candidates for endovascular repair by virtue of disease involving the ascending aorta or aortic arch that required clamshell incision and simultaneous repair. A total of 169 consecutive patients treated with open surgery for repair of chronic distal aortic dissection anatomically suitable to endovascular repair were included. This included 39 patients who underwent deep hypothermic circulatory arrest (DHCA) for proximal aortic control but were still included as potential candidates for stent-grafting that would have required coverage of the left subclavian artery (LSCA) by virtue of a short but adequate proximal landing zone.

Data were obtained from the prospectively maintained Cardiovascular Information Registry, and informed consent was waived by the institutional 

Abbreviations and Acronyms
$\mathrm{CI}=$ confidence interval
$\mathrm{CT}=$ computed tomography
$\mathrm{DA}=$ descending thoracic artery
DHCA $=$ deep hypothermic circulatory arrest
ET = elephant trunk
$\mathrm{HR}=$ hazard ratio
ICU = intensive care unit
$\mathrm{IQR}=$ interquartile range
LSCA $=$ left subclavian artery
TAA $=$ thoracoabdominal
TEVAR $=$ thoracic endovascular aortic repair

review board of the Cleveland Clinic. Eighty-eight patients had repair limited to the DA, and 81 patients had surgery involving the thoracoabdominal aorta (TAA) (Crawford type I in 27, Crawford type II in 54). Median interval from dissection to operation was 33 months (range, 10-86 months). Dissection extended into the abdominal aorta in 155 patients $(92 \%)$. Seventy-one patients $(42 \%)$ were treated for emergency or urgent indications, defined as rupture or impending rupture based on persistent symptoms and findings on computed tomography (CT) scan. Ninety-eight patients $(58 \%)$ had significant risk of rupture to warrant elective repair based on absolute size or growth rate. A total of 115 patients $(68 \%)$ had undergone prior cardiac surgery and 120 patients $(71 \%)$ had undergone prior aortic surgery, including 106 proximal repairs. Additional patient characteristics of interest included demographics, comorbidities, and morphology of disease (Table 1).

\section{Operative Technique}

All patients underwent a left posterolateral thoracotomy incision with or without TAA extension depending on the planned repair. Patients were anticoagulated with heparin, and most operations used complete or partial cardiopulmonary bypass, or left atrial to femoral bypass, with or without DHCA according to the surgeon's preference and extent of aorta repaired. The diseased aorta was then resected and replaced with an interposition synthetic graft, with reimplantation of intercostal and visceral branch vessels as indicated. Blood products were administered as necessary to correct coagulopathy, and all patients recovered in the intensive care unit (ICU). Operative details are listed in Table 1.

\section{Imaging Analysis}

Preoperative high-resolution CT scans were available in 124 patients $(73 \%)$ and systematically reviewed using a 3-dimensional imaging work station (Aquarius WS; Terarecon Inc, Mateo, Calif). Maximum diameter in a plane orthogonal to the center line of blood flow at 9 specific landmarks and overall maximum diameter were measured to ensure standardized assessment of each CT scan (Figure 1).

Patients with residual dissection distal to repair underwent additional CT scan analysis using the same 3-dimensional reconstruction software and methodology when images were available. Sixty-eight patients with residual dissection distal to the repair had at least 1 follow-up CT scan. In these patients, postoperative images were compared with preoperative CT scans to assess aortic growth and changes in aortic morphology.

\section{Outcome Definitions and Follow-up}

The primary outcome of this study was event-free survival: freedom from all-cause mortality and vascular reintervention, which was chosen to address both the safety and efficacy of the operation. Vascular reintervention was defined as reoperation or stent therapy on any part of the aorta or its branches. Follow-up included CT angiography at 3 months postoperatively and then annually. Patients followed at an outside institution were contacted by biennial mail surveys; questions pertained to symptoms, hospitalizations, and late vascular interventions. The Social Security Death Index was queried for the status of patients whose mortality data was not directly available through Cardiovascular Information Registry. Median survival follow-up was 23 months (interquartile range [IQR], 2-50). Median imaging follow-up in 124 patients with a preoperative CT scan was 7 months (IQR, 1-30).

Secondary outcomes included early (30-day) mortality, all-cause mortality alone, vascular reintervention alone, and morbidities associated with neurologic, respiratory, and renal complications. Neurologic complications included stroke (neurologic deficit $>72$ hours with CT documentation), paralysis (no movement of lower extremities), and paraparesis (lower-extremity weakness). Respiratory failure was defined as mechanical ventilation more than 5 days, reintubation, return to the ICU for respiratory support, or tracheostomy. Renal failure was defined as an increase in serum creatinine to more than $2 \mathrm{mg} / \mathrm{dL}$ or need for dialysis. Outcomes were stratified according to the extent of aortic repair: limited to the DA or extended to the TAA, defined as involvement of visceral or renal branch vessels in the repair.

\section{Statistical Analysis}

Continuous variables were described as mean \pm standard deviation or median (IQR), and categoric values were described as number ( $\%)$. The Kaplan-Meier method was used to evaluate survival and freedom from other outcomes, and differences between DA and TAA repair were assessed with the log-rank test. Univariable and multivariable Cox proportional hazard models were used to evaluate the relationship between the patient, operative, and CT characteristics and the primary and secondary outcomes. Variables associated with the outcomes with a $P$ value of .2 or less in the univariable analysis were chosen for the multivariable analysis. Variables with a $P$ value less than .05 in the multivariable analysis were associated with the outcomes. We also calculated the absolute mean differences in aortic diameter below the treated aortic segment between the last available CT scan and the preoperative CT scan. SAS 9.2 (SAS Institute Inc, Cary, NC) and S-Plus 6.0 (Insightful, Seattle, Wash) were used for all statistical analyses.

\section{RESULTS}

\section{Event-Free Survival}

Event-free survival after DA repair only $(80 \%, 69 \%$, $51 \%)$ and TAA repair $(69 \%, 62 \%, 47 \%)$ at 1,2 , and 5 years, respectively, is shown in Figure 2. There was no significant difference in event-free survival between those patients undergoing DA versus TAA repair. Twenty-nine patients $(33 \%)$ who underwent DA repair had a poor outcome (death or vascular reintervention), compared with 41 patients $(51 \%)$ who had TAA repair (univariable hazard ratio $[\mathrm{HR}], 1.3 ; 95 \%$ confidence interval $[\mathrm{CI}], 0.8-2.1$; $P=.2$ ). Larger maximum aortic diameter (per $1-\mathrm{cm}$ increase) before surgery (multivariable HR, 1.9; 95\% CI, 1.0-3.6, $P=.03$ ) at the level of the diaphragm (multivariable HR, 3.7; 95\% CI, 1.5-9.0; $P=.01$ ) or renal segment (multivariable HR, 4.3; 95\% CI, 1.2-15.7, $P=.03$ ) predicted late events. Patients with a history of coronary artery disease (multivariable HR, 2.1; 95\% CI, 0.9-5.0; $P=.09$ ) or congestive heart failure (multivariable HR, $2.3 ; 95 \% \mathrm{CI}$, $0.9-5.7 ; P=.07)$ also showed a trend toward mortality or reintervention within 5 years. 
TABLE 1. Patient characteristics and operative details

\begin{tabular}{|c|c|}
\hline & $\mathbf{n}=\mathbf{1 6 9}(\%)$ \\
\hline \multicolumn{2}{|l|}{ Demographics } \\
\hline Age $(y$, mean \pm SD) & $57 \pm 13$ \\
\hline Male (no.) & $139(82)$ \\
\hline Body mass index $\left(\mathrm{kg} / \mathrm{m}^{2}\right.$, mean $\left.\pm \mathrm{SD}\right)$ & $28 \pm 5$ \\
\hline \multicolumn{2}{|l|}{ Laboratory/tests (mean $\pm \mathrm{SD}$ ) } \\
\hline Ejection fraction $(\%)$ & $55 \pm 8$ \\
\hline Creatinine $(\mu \mathrm{mol} / \mathrm{L})$ & $106.1 \pm 70.7$ \\
\hline Creatinine (mg/dL) & $1.2 \pm 0.8$ \\
\hline \multicolumn{2}{|l|}{ Comorbidities (no.) } \\
\hline Hypertension & $157(93)$ \\
\hline Diabetes mellitus & $11(7)$ \\
\hline Smoking & $109(64)$ \\
\hline Coronary artery disease & $71(42)$ \\
\hline History of myocardial infarction & $37(22)$ \\
\hline Carotid disease & $69(40)$ \\
\hline History of cerebrovascular accident & $40(24)$ \\
\hline Peripheral vascular disease & $78(46)$ \\
\hline History of congestive heart failure & $24(14)$ \\
\hline \multicolumn{2}{|l|}{ NYHA functional class } \\
\hline Class I & $103(67)$ \\
\hline Class II & $54(32)$ \\
\hline Class III-IV & $12(7)$ \\
\hline Marfan syndrome & $27(16)$ \\
\hline Renal disease & $16(9)$ \\
\hline Chronic obstructive pulmonary disease* & $53(31)$ \\
\hline Prior cardiac surgery & $115(68)$ \\
\hline Prior aortic surgery & $120(71)$ \\
\hline Proximal & $106(62)$ \\
\hline Distal & $12(7)$ \\
\hline Both & $2(1)$ \\
\hline \multicolumn{2}{|l|}{ Extent of dissection (no.) } \\
\hline Limited to thoracic aorta & $14(8)$ \\
\hline Extensive & $155(92)$ \\
\hline Maximum aortic diameter $(\mathrm{cm}$, mean $\pm \mathrm{SD})$ & $6.13 \pm 1.12$ \\
\hline \multicolumn{2}{|l|}{ Indication (no.) } \\
\hline Elective & $98(58)$ \\
\hline Urgent/emergency & $71(42)$ \\
\hline \multicolumn{2}{|l|}{ Extent of repair (no.) } \\
\hline DA & $88(52)$ \\
\hline TAA & $81(48)$ \\
\hline Crawford type I & $27(16)$ \\
\hline Crawford type II & $54(32)$ \\
\hline \multicolumn{2}{|l|}{ Intraoperative details } \\
\hline ET completion & $56(33)$ \\
\hline Intercostal revascularization & $85(50)$ \\
\hline Visceral vessel revascularization & $81(48)$ \\
\hline Circulatory support & $157(93)$ \\
\hline \multicolumn{2}{|l|}{ Bypass technique } \\
\hline None & $12(7)$ \\
\hline Left atrial/pulmonary vein-femoral artery & $76(45)$ \\
\hline Femoral artery-femoral vein & $40(24)$ \\
\hline Axillary/subclavian artery-femoral vein & $29(17)$ \\
\hline Pulmonary artery-femoral artery & $7(4)$ \\
\hline Other & $5(3)$ \\
\hline Bypass time (min, median with IQR) & $83(53-141)$ \\
\hline
\end{tabular}

TABLE 1. Continued

\begin{tabular}{lc}
\hline & $\mathbf{n}=\mathbf{1 6 9}(\%)$ \\
\hline Circulatory arrest & $39(23)$ \\
Circulatory arrest time (min, median with IQR) & $23(19-32)$ \\
Aortic crossclamp time (min, median with IQR) & $39(26-70)$ \\
Cerebrospinal fluid drain & $75(44)$ \\
\hline NYHA, New York Heart Association; $S D$, standard deviation; $D A$, descending \\
thoracic artery; TAA, thoracoabdominal; IQR, interquartile range. *Forced expiratory \\
volume in 1 second less than 75\% of predicted or chronic inhaled or oral bronchodi- \\
lator therapy, with or without chronic steroid therapy aimed at lung disease.
\end{tabular}

\section{All-Cause Mortality}

Mortality data were available for all 169 patients. Fourteen patients $(8 \%)$ died within 30 days, and an additional 2 patients died in hospital after 30 days. Of the 14 deaths, 5 of these patients had DA repair and 9 of these patients underwent TAA repair $(P=.2)$. Causes of early death were multisystem organ failure $(\mathrm{n}=5)$, stroke $(\mathrm{n}=2)$, aortic dissection $(\mathrm{n}=2)$, acute pulmonary edema $(\mathrm{n}=2)$, sepsis $(\mathrm{n}=1)$, bleeding $(\mathrm{n}=1)$, and ventricular arrhythmia $(\mathrm{n}=1)$. Chronic obstructive pulmonary disease predicted early mortality (multivariable HR, 8.0; 95\% CI, 1.8-35.5; $P=.005)$. An additional 15 patients died within 1 year of surgery; 5 of these patients had been discharged to a longterm care facility. Actuarial survival after DA repair only $(84 \%, 74 \%, 54 \%)$ and TAA repair $(74 \%, 67 \%, 55 \%)$ at 1,2 , and 5 years, respectively, is shown in Figure 3, A.

\section{Vascular Reintervention}

Twenty-three patients (14\%) required vascular reintervention, including $8(9 \%)$ who underwent DA repair and $15(19 \%)$ who had TAA repair $(P=.07)$. A total of 40 additional operations were performed in these patients (14 proximal to repair, 12 involving the repaired segment, 14 distal to repair), including 22 endovascular procedures. Ten of these 40 reinterventions were at sites not contiguous with the original operation. Indications for reintervention included aneurysm with or without dissection $(n=24)$, pseudoaneurysm at an anastomotic site $(\mathrm{n}=8)$, mesenteric ischemia $(n=4)$, infected graft $(n=2)$, aortic rupture $(\mathrm{n}=1)$, and aortoesophageal fistula $(\mathrm{n}=1)$. Freedom for vascular reintervention after DA repair only $(95 \%, 91 \%$, $81 \%)$ and TAA repair $(89 \%, 85 \%, 79 \%)$ at 1,2 , and 5 years, respectively, is shown in Figure 3, $B$.

\section{Morbidity}

Mean length of stay in the ICU was 4 days (IQR, 2-7). Mean length of hospital stay was 11 days (IQR, 8-17). Sixty-six patients $(39 \%)$ had serious postoperative complications, including neurologic, respiratory, and renal. Serious neurologic events included stroke in 8 patients $(4.7 \%$, 4 with use of DHCA), paralysis in 2 patients $(1.2 \%$, neither with use of DHCA), and paraparesis in 2 patients $(1.2 \%$, neither with use of DHCA). There was no association between neurologic complications and use of circulatory 


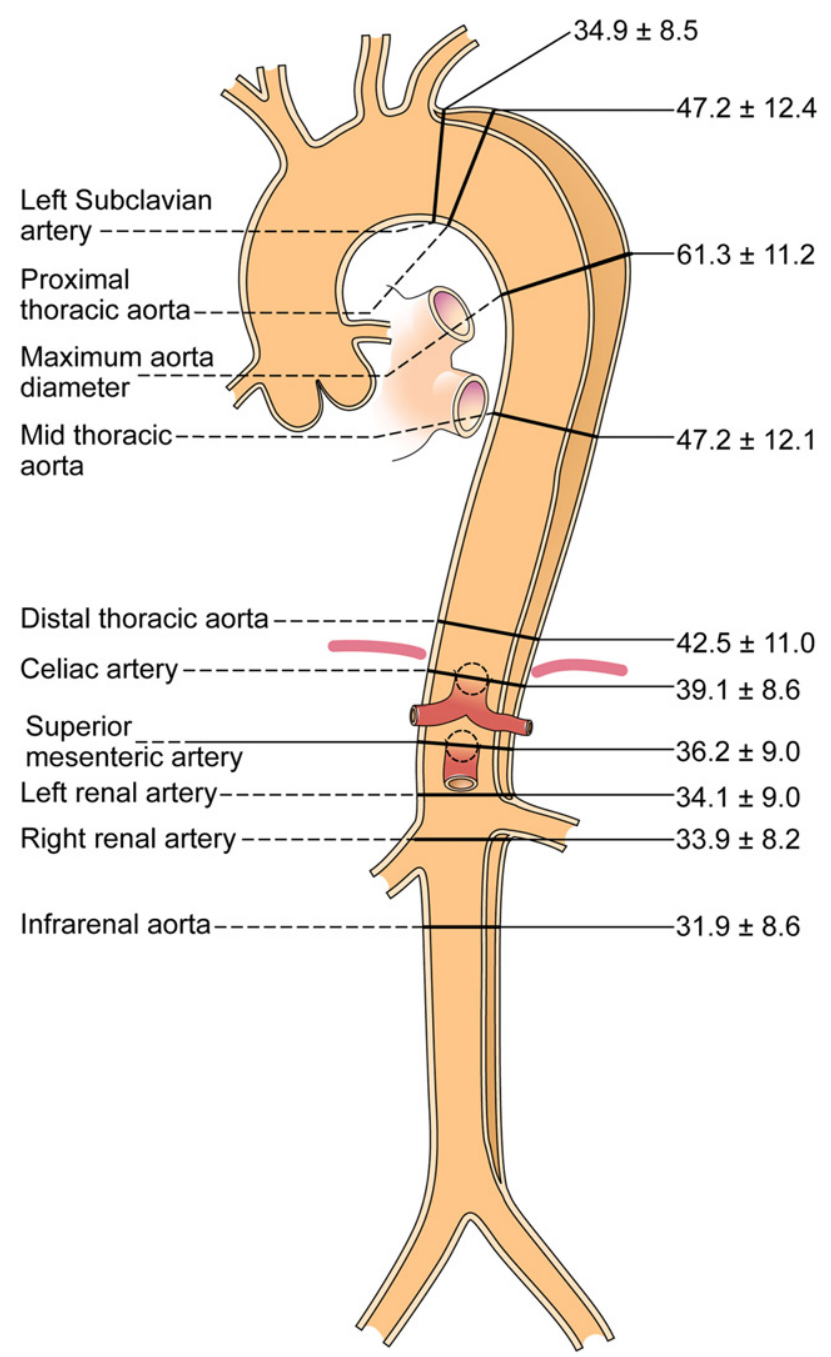

FIGURE 1. Maximum aortic diameter ( $\mathrm{mm}$, mean \pm standard deviation) at 9 segments and overall maximum diameter using 3-dimensional reconstruction (proximal thoracic aorta: $2 \mathrm{~cm}$ distal to LSCA origin; midthoracic aorta: level of inferior left pulmonary vein; distal thoracic aorta: $2 \mathrm{~cm}$ above celiac artery origin; infrarenal aorta: $2 \mathrm{~cm}$ below lowest renal artery; maximum aorta diameter: widest measurement in plane orthogonal to center line of flow between LSCA and infrarenal aorta).

arrest. Patients with TAA were more likely to have respiratory failure requiring tracheostomy or renal failure than patients with DA. Thirty-two patients had postoperative respiratory failure, including 13 who had DA repair and 19 who had TAA repair $(P=.6)$. Patients with postoperative respiratory failure who underwent TAA surgery were more likely to require tracheostomy (4 with DA, 11 with TAA, $P=.04)$. Postoperative renal failure was almost exclusive to patients who had TAA repair and occurred in 17 patients $(21 \% ; 15$ required hemodialysis [ 5 temporary and 10 permanent, including 6 deaths]) in this group compared with only 1 patient ( $1 \%$; did not require hemodialysis) in the DA group $(P<.001)$. None of the 169 patients had a myocardial infarction.

\section{Aortic Diameter and Growth}

Mean preoperative aortic diameters at 9 designated landmarks in 124 patients are shown in Figure 1. Patients who underwent TAA repair had significantly larger aortas at all 9 segments. Overall mean maximum aortic diameter before surgery was $6.13 \pm 1.12 \mathrm{~cm}$.

Sixty-eight patients with residual dissection distal to repair had at least 1 follow-up CT scan. Fifty-one patients had a follow-up CT scan at least 1 year after surgery. Three-year imaging follow-up was available in 25 patients. Growth in the untreated segment was increasingly greater at more distal aspects of the abdominal aorta. Growth at various segments is shown in Figure 4.

\section{DISCUSSION}

As the survival after aortic dissection has improved, more patients with chronic dissection require treatment of late complications. Although thoracic endovascular aortic repair (TEVAR) now plays a primary role in the treatment of distal aortic pathology, its success in patients with chronic dissection has been relatively unpredictable. For this reason, we have limited our use of TEVAR in patients with chronic dissections to those with limited extents of dissection or high risk for open repair. Consequently, the majority of patients undergoing open repair in the current era have extensive aortic dissection involving both the thoracic and abdominal segments, consistent with the extensive dissection in $92 \%$ of patients reported in this article. Approximately half were treated under urgent or emergency conditions. Despite the severity of disease, survival at 30 days was $92 \%$ and occurrence of spinal cord injury was only $2.4 \%$, which represents a favorable perioperative outcome comparable to other experiences from centers of excellence and endovascular experiences. ${ }^{6-9}$ These early results are attributable to advances in perioperative care, perfusion techniques, and increased surgeon experience as the volume of patients treated for aortic dissection increases. ${ }^{1}$

Because the morbidity of open repair is correlated with the extent of repair, the accepted surgical strategy is to limit the extent of resection for this disease process to the segments most at risk for rupture or late complications. ${ }^{6,10}$ For this reason, the extent of repair was almost evenly divided between DA and TAA despite the presence of extensive dissection in this population. The findings of the study support this strategy. The low paraplegia rate is in part attributable to this strategy and the use of adjuncts, such as cerebrospinal fluid drainage with intrathecal papaverine, active cooling, limiting spinal cord collateral steal, and judicious use of intercostal reimplantation. For all elective operations involving the distal arch, LSCA patency was maintained. In patients whose elephant trunk (ET) anastomosis was performed between the left carotid and LSCA, the LSCA was reconstructed during open DA repair or before repair with a carotid to LSCA bypass. 


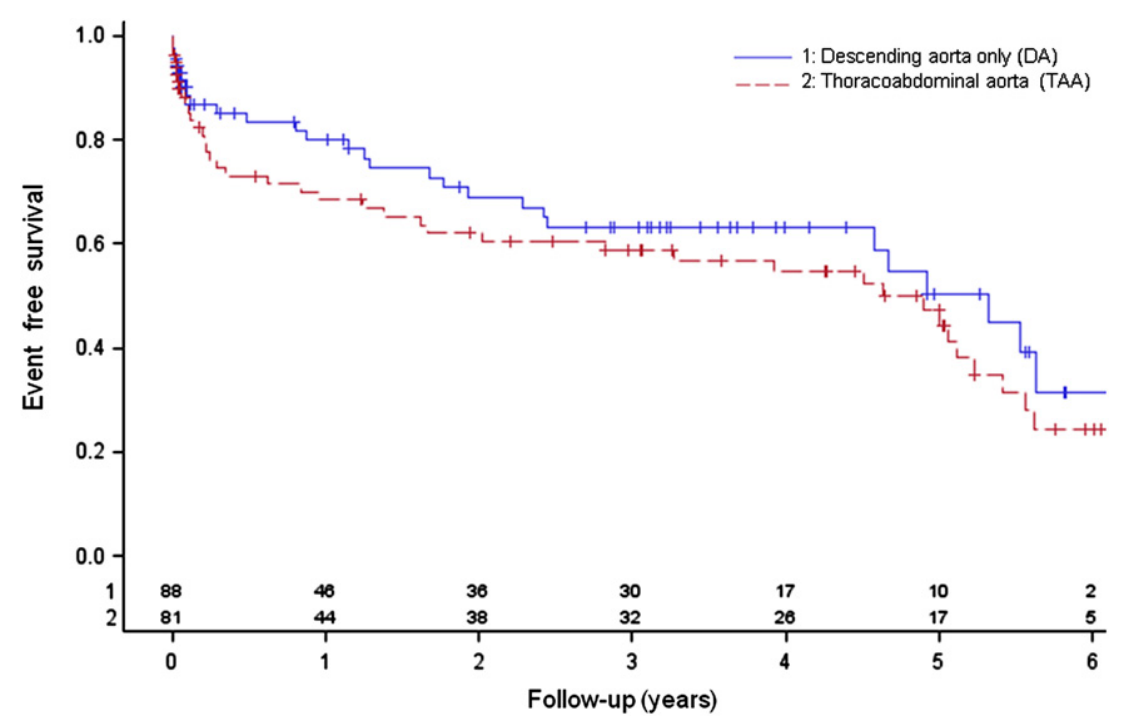

FIGURE 2. Kaplan-Meier estimate of event-free survival (freedom from all-cause mortality and vascular reintervention) by extent of repair, expressed as probability with number at risk.

Although we did not see a difference in early mortality, DA repair was associated with less perioperative morbidity than TAA repair. This was especially true for respiratory and renal complications. Of note, TAA was not protective of late reintervention, and the risk of death or reintervention was high in both groups. This is in part due to the residually dissected aorta distal to repair continuing to be at risk for aneurysmal degeneration and in part due to the baseline aortopathy seen in many of these patients (mean age of 57 years and $16 \%$ with documented Marfan syndrome). Therefore, routine imaging follow-up is critical in all of these patients.

A greater degree of aneurysmal degeneration in terms of both maximum aortic diameter and more distal diameters was predictive of poor outcome, and so it is reasonable to pursue treatment strategies directed at achieving earlier remodeling and stabilization of the chronically dissected aorta in patients at risk for aneurysmal degeneration. Nonetheless, early stent-grafting of all patients with distal dissection was not validated by the INSTEAD trial. ${ }^{11}$ Currently, however, our ability to detect patients at risk for aneurysmal degeneration is limited. It has been shown that false lumen patency, aortic diameter greater than $4 \mathrm{~cm}$ or false lumen diameter greater than $22 \mathrm{~mm}$, and, possibly, circumferential dissection are predictive of late aortic enlargement. ${ }^{2,12}$

Previous reports of patients treated approximately 2 decades earlier describe similar short- and intermediate-term outcomes with early mortality ranging from $5 \%$ to $10 \%$ and 3-year survival of $71 \%$. Although late survivals have not changed over time, the populations are probably not comparable. Unlike the previous reports in the literature, most of these patients have more extensive disease because of the increased use of stent-grafts in patients with limited disease. Furthermore, this experience describes a discrete population of patients, all with chronic distal dissection and proximal anatomy suitable to stent-grafting.
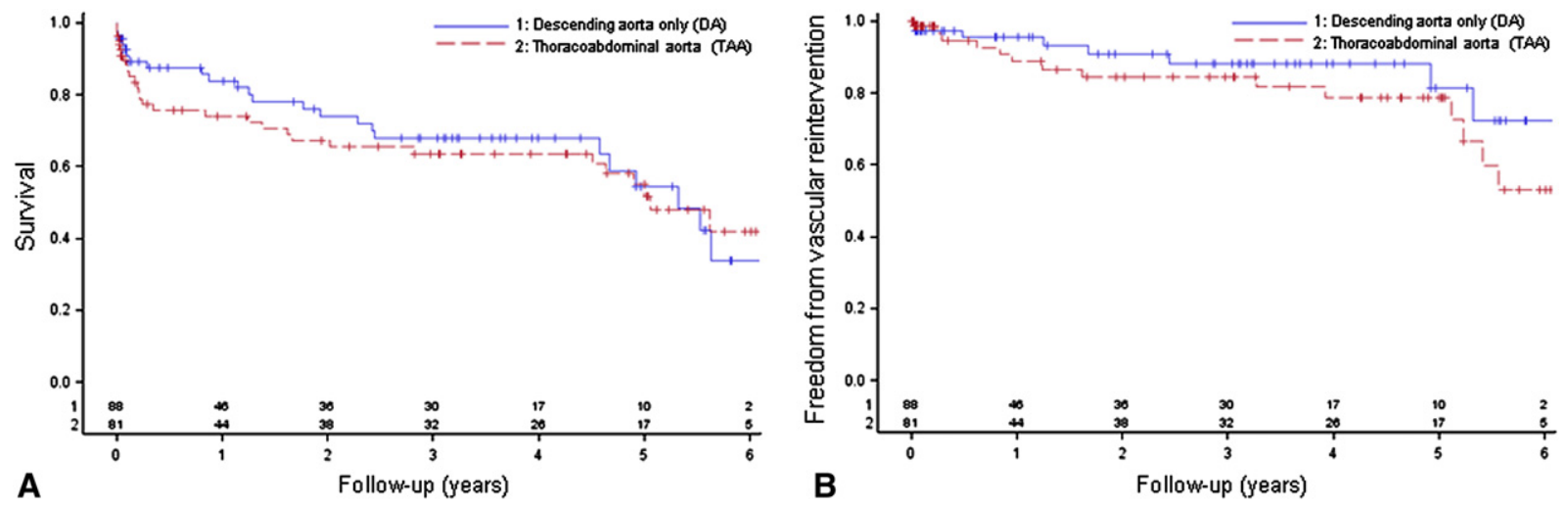

FIGURE 3. A, Actuarial survival by extent of repair, expressed as probability with number at risk. B, Kaplan-Meier estimate of freedom from vascular reintervention by extent of repair, expressed as probability with number at risk. 


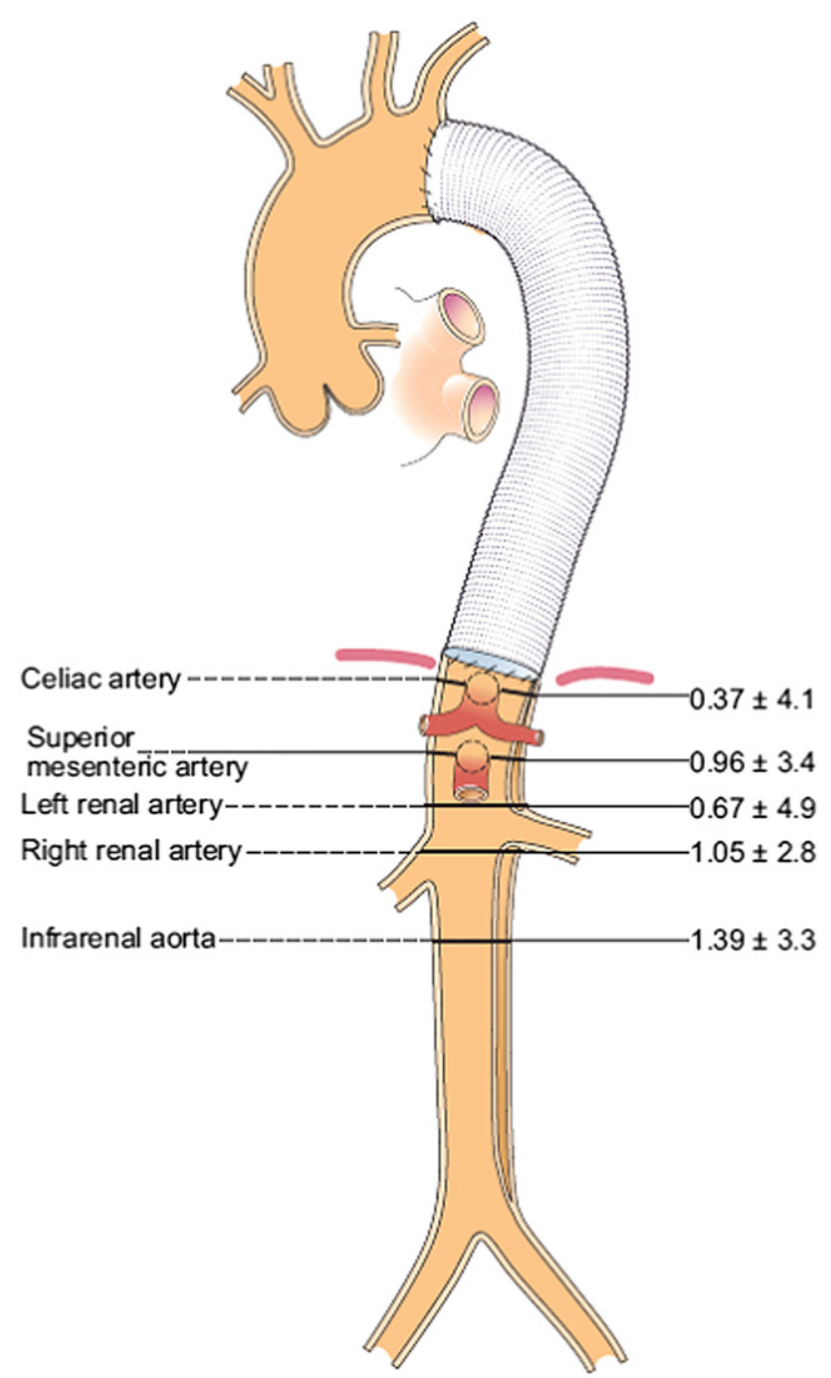

FIGURE 4. Aortic growth distal to repair ( $\mathrm{mm}$, mean \pm standard deviation).

\section{Endovascular Era}

The risks of open surgical repair of chronic distal aortic dissection coupled with technologic advances have prompted an interest in the use of endovascular stent-grafts for treatment of this disease. Results have been varied thus far and limited to small groups of patients. A metaanalysis published in 2006 compiled outcomes data from 39 studies of distal aortic dissection, which included 197 patients treated with endovascular stent-grafting in the chronic phase. Thirty-day mortality was $3.2 \% \pm 1.4 \%$, with a 1-year survival of $92.7 \% \pm 2.1 \%$ and $91.1 \% \pm 2.6 \%$ at 2 years. ${ }^{8}$ In another series of 61 patients treated with endovascular repair for chronic distal aortic dissection between 1997 and 2005, 30-day mortality was 3.3\% and intermediate-term survival was $93 \%$ with a mean followup of $35.9 \pm 28.5$ months. ${ }^{9}$ At the Cleveland Clinic, 76 patients considered high risk for open surgery underwent
TEVAR for chronic distal aortic dissection between 2000 and 2007. Intermediate-term survival was favorable compared with the 169 patients who underwent open surgery in the current report $(86 \%, 82 \%$, and $80 \%$ at 12,24 , and 36 months, respectively). However, the patient population was different. Although the patients selected for endovascular therapy were older, many of them had limited extents of dissection involving only the DA, in stark contrast with those undergoing open repair, with $92 \%$ having the dissection extend through the abdominal aorta. Nonetheless, freedom from death and vascular reintervention was similar $\left(72 \%, 64 \%\right.$, and $59 \%$ at similar time points). ${ }^{13}$

Subsets of patients who underwent hybrid repair at the Cleveland Clinic since 2000 have also been described. From 2001 to 2010, 50 patients underwent hybrid frozen ET repair (19 reverse), and an additional 22 patients underwent hybrid arch debranching over the same period. ${ }^{14,15}$ These patients were high risk and selected on the basis of need for repair of extensive pathology, anatomic difficulties, or urgent intervention. Mean follow-up in the patients with frozen ET was 17 months (range, 1-76 months), and actuarial survival was $87 \%$ at 2 years.

Of the 169 patients in the current series, 108 had previous type A dissection. Aortic reconstruction using a 2-staged ET approach in the late chronic phase is commonly used in such patients to permit surgical flexibility, including the performance of simultaneous cardiovascular procedures. Newer techniques, such as the frozen ET repair for extended repair of acute type A dissection, are increasingly being used at the Cleveland Clinic and other centers. The early outcomes are reasonable, but the value of such an approach requires further investigation and may prove to be most appropriate in those at high risk for later reintervention. ${ }^{16,17}$

\section{Open or Endovascular?}

Although perioperative and intermediate-term results of endovascular repair of chronic distal aortic dissection appear favorable, many of the patients in these series have disease limited to the thoracic aorta, and thrombosis of the false lumen in the treated segment was achieved in only $75 \%$ to $83 \%$ of patients. ${ }^{8,9}$ Of note, $37 \%$ of patients undergoing endovascular repair in the largest series died or required endovascular or open surgical reintervention within a 3-year follow-up period. ${ }^{9}$ With open surgical repair, the risk of aneurysm-related death in the treated segment is eliminated by resection. With endovascular treatment, aortic remodeling is only consistently predictable in patients in whom the dissection is limited to the thoracic aorta with accessible proximal and distal seal zones. ${ }^{13,18}$ For this reason, it has been recommended that endovascular repair be limited to only patients with limited dissections or considered high risk for open surgery. Because most high-risk patients are older, it could be argued that aortic intervention be delayed because the 
short-term morbidity benefit of endovascular repair may come at the expense of an increased risk of vascular reintervention or late complications. ${ }^{19}$ However, the data in this study suggest that patients with extensive dissection and later stages of aneurysmal degeneration have poor outcomes even after successful surgical repair of the most dangerous segments of aorta.

Patients with chronic obstructive pulmonary disease may particularly benefit from a less-invasive procedure without the physiologic stresses of a chest incision. Patients who had open repair of the TAA were also more likely to have serious postoperative pulmonary and renal complications than those undergoing repair limited to the DA. This approach often requires at least partial division of the diaphragm and an obligate period of renal malperfusion. Larger maximum aortic diameter and larger diameter more distally at the diaphragm or the renal segment were predictive of poor outcome, regardless of extent of repair. These findings demonstrate the dangers of waiting to treat patients until they have advanced disease. Patients requiring more extensive repair and with larger aortas may be considered for staged procedures or as candidates for randomization to surgery or endovascular repair.

\section{Limitations and Implications}

The results of this study are limited by the experience of a single center and the common difficulties of data collection in a retrospective analysis. Preoperative CT scans were unavailable for review in patients who presented with reports of $\mathrm{CT}$ findings from outside institutions. In this same population, obtaining follow-up CT scan results was attempted but often difficult and incomplete. Cause of death was not available for all patients. Although late outcomes were poor in this series and aortic death could not be excluded, these patients represent a relatively sick population and causes of death were likely variable.

Furthermore, the surgeon's selection bias regarding repair approach cannot be accounted for by a retrospective study. Thus, any comparison between historic results of open surgery and endovascular repair for distal aortic dissection should be made with caution and only between patient populations with matched baseline characteristics. The controversy regarding open surgery versus endovascular repair for chronic distal aortic dissection will persist until a randomized trial addresses the issue of matching patients to reliably compare outcomes between these 2 techniques. Such a trial is necessary to definitively determine the preferred repair approach for each individual patient by taking into account demographics, comorbidities, and anatomic considerations. However, not all patients with chronic distal aortic dissection would be randomized to either intervention when the surgeon's empiric evidence and the available literature suggest that a given patient may benefit more from one procedure over the other. The data from this study would, however, suggest there would be reasonable equipoise from a randomized comparison. Thus, an enriched randomized trial of open surgery versus endovascular repair for repair of chronic distal aortic dissection in high-risk patients, as identified by this analysis, would be appropriate.

\section{CONCLUSIONS}

Early outcomes are good and late outcomes are less than desirable after open repair of complicated chronic distal aortic dissection, regardless of the extent of repair. High-risk and late-stage patients with larger and more extensive aneurysmal degeneration warrant further investigation, including the use of newer, less-invasive techniques. Select patients at risk for aneurysmal degeneration should undergo a more aggressive initial approach with aortic dissection repair.

The authors thank Edward R. Nowicki, MD, for insights and assistance in the design of this study.

\section{References}

1. Olsson C, Thelin S, Ståhle E, Ekbom A, Granath F. Thoracic aortic aneurysm and dissection: increasing prevalence and improved outcomes reported in a nationwide population-based study of more than 14,000 cases from 1987 to 2002. Circulation. 2006;114:2611-8.

2. Subramanian S, Roselli EE. Thoracic aortic dissection: long-term results of endovascular and open repair. Semin Vasc Surg. 2009;22:61-8.

3. Chaikof EL, Mutrie C, Kasirajan K, Milner R, Chen EP, Veeraswamy RK, et al. Endovascular repair for diverse pathologies of the thoracic aorta: an initial decade of experience. J Am Coll Surg. 2009;208:802-16.

4. Green GRi, Kron ILi. Aortic dissection. In: Cohn LH, Edmunds LH Jr., eds. Cardiac Surgery in the Adult. 3rd ed. New York, NY: McGraw-Hill; 2003. p. 1095-122.

5. Erbel R, Alfonso F, Boileau C, Dirsch O, Eber B, Haverich A, et al. Task Force on Aortic Dissection, European Society of Cardiology. Diagnosis and management of aortic dissection. Eur Heart J. 2001;22:1642-81.

6. Svensson LG, Crawford ES, Hess KR, Coselli JS, Safi HJ. Dissection of the aorta and dissecting aortic aneurysms. Improving early and long-term surgical results. Circulation. 1990;82(5 Suppl):IV24-38

7. Safi HJ, Miller CC 3rd, Reardon MJ, Iliopoulos DC, Letsou GV, Espada R, et al. Operation for acute and chronic aortic dissection: recent outcome with regard to neurologic deficit and early death. Ann Thorac Surg. 1998;66:402-11.

8. Eggebrecht $H$, Nienaber $C A$, Neuhauser $M$, Baumgart $D$, Kische $S$, Schmermund A, et al. Endovascular stent-graft placement in aortic dissection: a meta-analysis. Eur Heart J. 2006;27:489-98.

9. Alves CM, da Fonseca JH, de Souza JA, Kim HC, Esher G, Buffolo E. Endovascular treatment of type B aortic dissection: the challenge of late success. Ann Thorac Surg. 2009;87:1360-5.

10. Greenberg RK, Lu Q, Roselli EE, Svensson LG, Moon MC, Hernandez AV, et al. Contemporary analysis of descending thoracic and thoracoabdominal aneurysm repair: a comparison of endovascular and open techniques. Circulation. 2008; 118:808-17.

11. Nienaber CA, Rousseau H, Eggebrecht H, Kische S, Fattori R, Rehders TC, et al., INSTEAD Trial. Randomized comparison of strategies for type B aortic dissection: the INvestigation of STEnt Grafts in Aortic Dissection (INSTEAD) trial. Circulation. 2009;120:2519-28.

12. Marui A, Mochizuki T, Mitsui N, Koyama T, Kimura F, Horibe M. Toward the best treatment for uncomplicated patients with type B acute aortic dissection: A consideration for sound surgical indication. Circulation. 1999;100(19 Suppl):II275-80.

13. Kang WC, Greenberg RK, Mastracci TM, Eagleton MJ, Hernandez AV, Pujara AC, et al. Endovascular repair of complicated chronic distal aortic dissections: intermediate outcomes and complications. J Thorac Cardiovasc Surg. 2011;142:1074-83.

14. Roselli EE, Soltesz EG, Mastracci T, Svensson LG, Lytle BW. Antegrade delivery of stent grafts to treat complex thoracic aortic disease. Ann Thorac Surg. 2010;90:539-46. 
15. Lima B, Roselli EE, Soltesz EG, Johnston DR, Pujara AC, Idrees J, et al. Modified and "reverse" frozen elephant trunk repairs for extensive disease and complications after stent grafting. Ann Thorac Surg. 2012;93: 103-9.

16. Sun L, Qi R, Zhu J, Liu Y, Zheng J. Total arch replacement combined with stented elephant trunk implantation: a new "standard" therapy for type a dissection involving repair of the aortic arch? Circulation. 2011;123: 971-8
17. Bavaria J, Milewski RK, Baker J, Moeller P, Szeto W, Pochettino A. Classic hybrid evolving approach to distal arch aneurysms: toward the zone zero solution. $J$ Thorac Cardiovasc Surg. 2010;140(6 Suppl):S77-80.

18. Rodriguez JA, Olsen DM, Lucas L, Wheatley G, Ramaiah V, Diethrich EB. Aortic remodeling after endografting of thoracoabdominal aortic dissection. $J$ Vasc Surg. 2008;47:1188-94.

19. Svensson L. Aortic dissection endovascular stenting: less pain, survival gain? Ann Thorac Surg. 2009;87:1332-3. 